Brit. J. vener. Dis. (1966), 42, 223.

\title{
EDITORIAL
}

\section{THE BRITISH VENEREAL DISEASES SERVICE, 1916-66}

In 1916, the Public Health (Venereal Diseases) Regulations required County Councils and County Borough Councils in Great Britain to establish special clinics for the treatment of venereal diseases and to make arrangements for providing laboratory aids to diagnosis. These services were to be free and confidential. The British Venereal Diseases Service thus came into being and its jubilee this year, although receiving no official celebration, should not be allowed to pass un-noted.

The Public Health (Venereal Diseases) Regulations of 1916 gave administrative effect to the main recommendations contained in the Final Report, published by H.M. Stationery Office (Cmd. 8189) in 1916, of the Royal Commission on Venereal Diseases which began its work in 1913. The dramatic discoveries of the previous decade, which included the identification of T. pallidum (Schaudinn, 1905), the introduction of the Wassermann Reaction in 1906, and the development of Salvarsan by Ehrlich during 1909 and 1910, played a significant part in the timing of the setting up of the Royal Commission. The Commission's Report made 35 recommendations, including proposals for the instruction of medical students and practitioners about the venereal diseases and for education of the public in the dangers of these diseases, in addition to the provision of free and confidential facilities for diagnosis and treatment. The Regulations were implemented with commendable speed and in most parts of the country the special clinics registered the first of their many patients during the later months of 1916.

The difficulties which had to be met and overcome by the rapidly improvised special clinics must have daunted all but the stoutest hearts in those dark days midway through the first world war: inadequate accommodation and equipment; shortage of trained staff; the widespread social stigma attaching to the diseases and to those who suffered from them (not excluding those doctors and nurses who came forward to develop the new V.D. Service); and the view that venereal diseases were incurable, which was widely held by the mass of the population, who normally sought medical advice and treatment for any illness only when it caused incapacity or unbearable suffering. The prevalence of venereal disease was high; the Royal Commission, on the pre-war evidence available, declared that the number of persons infected with syphilis could not be below 10 per cent. of the population in the large cities, and that the percentage affected with gonorrhoea greatly exceeded this figure. Doubtless, these infections became even more prevalent during the war years, 1914-18, and thus the V.D. Service in its early, formative stage had to meet both the backlog of disease untreated during previous years and the high prevalence of the more recent infections arising both at home and overseas during wartime.

Throughout the 1920s the development and improvement of the V.D. Service were due to various factors; the availability of doctors and technicians coming back to civil practice with extensive experience in the management of the venereal diseases gained in the fighting Services; improved out-patient accommodation increasingly provided in ad hoc clinics or at municipal hospitals often with some provision for in-patients; technical advances in, and improved standards of performance of, the 
diagnostic tests in the clinics or in the associated laboratories; increasing awareness of the need for more adequate courses of arsenotherapy associated with a heavy metal and prolonged follow-up in the management of syphilis; the appreciation that urethritis responded better to gentler measures and more dilute irrigating fluids than those formerly used; and more widespread efforts in tracing sources of infection and contacts. Increasingly in the 1930s the clinic doctors became primarily interested in venereology rather than regarding it as a supplementary source of income whilst mainly engaged in some other branch of medical practice; this trend, with few exceptions, has established itself fully in the past 20 years.

With the introduction of the National Health Service in 1948, Regional Hospital Boards and Boards of Governors took over responsibility for the V.D. Service which was effectively dealing with the venereal aftermath of the second world war. By now most venereologists were well-trained physicians with a specialized knowledge of all the aspects of the venereal diseases and fully merited the consultant grading accorded to their peers in the other specialized branches of medicine. The work of the V.D. Service is described in the Annual Reports of the Chief Medical Officer to the Ministry of Health, and over the years these Reports provide a record which we may view with some pride but without complacency. The Medical Society for the Study of Venereal Diseases, founded in 1922, and this Journal, have both made valuable contributions to the development and the present high standards of the V.D. Service, and thus we can take an almost personal pleasure in congratulating and paying tribute to all those who have played a part in the work of the V.D. Service during its first 50 years.

What of the future? There is still room for improvement in the diagnosis of gonococcal infection in the female, in the understanding and management of non-specific urethritis in the male, in contact-tracing, and in the educational, social, and behavioural fields in which lie the main hopes of prevention. The need for an efficient, specialized V.D. Service will continue as far as the future can be forecast and no doubt this can and will be provided. The greatest anxiety which clouds the future of the V.D. Service as it enters its second half-century is its failure to attract young, well-trained physicians to this special field. Many of our venereologists are approaching the end of their professional lives and must soon pass on the "torch"; more must be done to ensure that "the host behind" is ready to receive it. 